Among investigations in progress noted by the director in his report are an entomological inventory of the different natural regions as a prelude to a study of their fauna and a study of the entomological fauna of the remains of the primary forests still existing in Ruanda-Urundi; investigations on the cycle of trypanosomes; and studies of climatic and technical problems in tropical habitation. Other studies have related to the control of malaria among children in the plain of Ruzizi and the territory of Uvira, the transmission of trypanosomiasis by Glossina brevipalpis on the River Malagarasi, the use of electrophoretic diagrams in nutrition studies, such as in a case of kwashiorkor, morphometric studies of the lakes of Bulera, Luhondo, Mohasi, Mugesera, Bilala, Sake and Bugwero, in Ruandi, including also plankton studies and the study of the littoral fauna. Therapeutic studies of kwashiorkor, studies of the incidence of goitre in Ruanda, of the sensory physiology of the tsetse, a physico-chemical and hydrobiological study of Lake Gileppe, near Verviers, and of the variation with altitude of the potential gradient of the sun have also been made, and biochemical methods applied to the determination of proteins, protein fractions, lipids and cholesterol of blood.

Intraspecific variations among Hyperolius viridiflavus and $H$. lateralis have been studied in Ruanda and Urundi; Schoutedenella mossooensis sp. n. du Mosso, probably a new race of Hyperolius cinnamomeoventri, a Congo species encountered for the first time in Ruanda in the valley of the Akamyaru, was captured as well as three other species not previously captured in Ruanda-Urundi: Atractaspis bibroni rostrata, Hyperolius oxyrhynchus and Schoutedenella lameerei. An inventory and ecological study were made of some arthropods of the Great Lakes, and a study of the indigenous political organization of the kingdom of Ruanda was completed for presentation as a thesis. An inquiry into the migrations and biology of the fish of a river torrent in the Tanganyika basin, studies of the syncline of Itombwe between Lakes Kivu and Tanganyika and of the frequency of the sickle-cell trait, examination of anthropometric practices in Ruanda-Urundi, the prehistoric industry of the plain of the Lemba, anæmia in states of malnutrition and paludism in mammals and the invertebrate hosts are also noted, as well as the reorganization of the system of demographic inquiry in RuandaUrundi.

\section{HOP PICKING BY MACHINE}

$\mathrm{S}^{\mathrm{r}}$

INCE the Second World War, shortage of labour for picking hops by hand has forced English growers in increasing numbers to turn to the use of picking machines. In 1947 it was estimated that not more than eight machines were in use; the figure had increased to more than a hundred machines in 1954 and a further hundred machines are on order for 1955. These machines are mainly large stationary types which are best suited to the needs of growers of larger acreages. Smaller machines are being produced for the smaller growers, so it is probable that within a few years English hops will be picked mainly by machine.

These developments have been kept under observation by the Department of Hop Research of Wye College, Kent. Each year from 1949 until 1953 inclusive, the Department, with encouragement and financial help from the Agricultural Research Council, has organized surveys of picking machines at work on the farms of commercial growers. The results of these surveys have been published in detail in the annual reports of the Department for the years 1950-53 inclusive. At the request of the Hops Marketing Board, the findings of the surveys have been summarized in an article by $G$. P. Chater and Miss C. L. Jary*.

The main point emerging from the surveys is the importance of intelligent and efficient management ; the best of picking machines will give poor results if badly managed.

The concept of machine picking as a factory process is a valid one. From plant to pocket the hops pass along a production line, and, as in all mechanized industries, good management based on a clear understanding of the process as a whole is essential if a good final sample of dried hops is to be produced.

The chief disadvantage of all picking machines is the amount of breakage they cause to the hop cones. Such breakage makes for difficulties in subsequent cleaning and drying and may lead to wastage of hop material in general and of resins in particular. The subject of resin-loss is a controversial one. An investigation is nearing completion at Wye in which a series of forty-two pairs of pocket samples from the 1954 crop is being examined. Each pair consists of hops of the same variety and from the same farm, one sample of each pair being hand picked and the other machine picked. Preliminary results show that in thirty-five of the forty-two pairs of samples the hand-picked hops appear to have more resin than the machine-picked ones; in the remaining seven pairs the machine-picked hops appear to have a higher resin content than the hand-picked samples.

One of the most important objects of future research on machine picking must be to reduce damage to the cones. In addition to preventing wastage and improving drying performance, such reduction in the breakage of cones would reduce the risk of resin-loss. Future research in England may also have to pay attention to the cleaning of machinepicked hops. In the United States, picking machines have been in general use for some ten years and more than 90 per cent of the crop there is now picked by machine. American growers are now producing by machine-picking large quantities of dried hops with less than 2 per cent by weight of leaf and stem. Data collected in the Wye College surveys suggest that English machine-picked hops have from 3 per cent to 12 per cent of leaf and stem and that hand-picked hops have 3-6 per cent ; such information is too scanty to permit of large generalizations. It is possible, moreover, that the relative eleanness of American machine-picked hops is achieved by tolerating a degree of wastage of broken hops that could not be accepted at present in England. This aspect of machine picking would appear to merit investigation.

In the Wye College surveys the approach was that of the hop grower rather than that of the agricultural engineer. This approach was the only one permitted by the circumstances and has yielded valuable results. It has, however, obvious limitations, and the time has come for research on picking machines, and on the related problem of the drying of machinepicked hops, to be taken up by a team of agricultural engineers.

If research on the machine becomes the responsibility of the agricultural engineer, the growing of * Obtainable from the Secretary, Wye College, Ashford, Kent. $1 s$. 
hops for the machine remains the responsibility of the hop grower.

The correct interpretation of the results of all this work demands more knowledge of how the hop plant grows than is at present available. It is hoped that it may soon be found possible to appoint a plant physiologist at Wye College to make a detailed study of the pattern of growth of the hop plant.

\section{THE HANDICAPPED CHILD}

TN a school population of approximately $5,970,000$ 1 in England and Wales, 16,719 were pupils known to school medical officers to be physically handicapped. The most frequently recorded conditions responsible for the handicap included heart disease $(4,453)$, cerebral palsy (2,954), deformities and amputations of the limbs $(2,053)$, poliomyelitis $(2,001)$, tuberculosis $(1,766)$ and spina bifida $(543)$. It is estimated that only about one child in every thousand is too severely handicapped to become entirely selfsupporting and to be able to live a full life. The increasing emphasis of recent years upon the advisability of keeping such children at home has added considerably to the responsibility involved in the care of these children. It is not only in the case of the deaf child that there is often more than one patient. Indeed, there are often three, for both parents as well as the child have to be considered. No handicapped child can achieve the optimum enjoyment of life unless the parents are prepared to carry out to the full the instructions of their medical advisers.

The family doctor's responsibility in dealing with these unfortunate children is threefold. In the first place he must be on the look-out for any handicap so that he can detect it at the earliest possible age and refer the child to a specialist for advice as to what can be done to overcome, or at least ameliorate, the disability. Secondly, he must know of the organizations, voluntary and statutory, which are available to help such children. Thirdly, there is the supervision and care of the child in the home.

All these aspects are dealt with in a remarkably good issue of The Practitioner (174, No. 1042; April 1955), which includes articles by specialists on children's disabilities.

\section{BREEDING BEHAVIOUR OF THE AMERICAN COOT}

COME peculiarities in the breeding behaviour of $S$ the American coot (Fulica americans) have been described by G. W. Gullion (Auk, 71 ; October 1954).

The bird is probably always monogamous in its sexual behaviour. If one mate disappears during the nesting season, a second mate may be accepted within forty-eight hours. Among the resident coots with secure territories, pairing seems to be as permanent as the life of the birds or their ability to maintain a territory.

Coots breed in a habitat which contains abundant nesting material, and they use this material freely in constructing floating structures associated with breeding. These structures are bulky, and since materials seldom present a procurement problem, they are not built for permanence but must be added to repeatedly while in use. Eggs are seldom laid in more than two of the eight or nine structures which are usually built. The other structures are utilized for resting, roosting and brooding sites.

Three types of structures built by coots-a display platform, the egg nest and a brood nest-follow one another in a definite sequence, and breeding events can be reliably predicted by their appearance. Certain modes of construction permit the identifica. tion of a nest type even before it is placed in use.

Copulation normally, perhaps always, takes place on a display platform. There is little or no precopulatory display or chase, and the two birds resume normal activity within two or three minutes following copulation. Eggs may appear before the nest is completed and are laid daily in the very early hours of the morning. The nest is completed and lined by the time the clutch is complete.

Incubation is continuous and is shared by both sexes, the male probably doing the greater share of it.

When deposition of the clutch is just beginning the female incubates all night, but otherwise the male incubates from dusk to dawn; the female always takes about a four-hour shift at dawn and then shifts of about one-hour duration follow until sunset. Young coots are quite helpless until a day or so old and require prolonged parental care. The male parent does most of the brooding during the staggered hatching period, while the female brings food to the nestlings and takes the older ones away to feed and brood. Later, the parents divide the brood during feeding and brooding.

\section{CHLOROPLAST STRUCTURE}

$\mathrm{T}$ a study of the structure and swelling properties 1 of the chloroplasts of Nitella cristata, F. V. Mercer, A. J. Hodge, A. B. Hope and J. D. McLean have made some new and interesting observations and stated some tentative conclusions (Austral. J. Biol. Sci., 8, 1, 1; 1955). Electron-microscope studies of ultra-thin sections have shown that the normal chloroplast consists of about 40-100 lamellæc.70 A. apart, enclosed by an external membrane c. $70 \mathrm{~A}$. thickness. Grana do not occur. The space within the chloroplast not occupied by the lamellæ is filled with a granular material resembling the cytoplasm. The chloroplast often contains a considerable number of osmiophilic globules c. $0 \cdot 1 \mu$ in diameter lying between the lamellæ, their staining reaction with osmic acid indicating that they are probably lipoidal.

Numerous small osmiophilic bodies c. $100 \mathrm{~A}$. or less in diameter are associated with the lamellæ. Starch grains, when present, occur between the lamellæ and appear to be enclosed within by a membrane. During swelling in hypotonic solutions, chloroplasts change in shape from disk to sphere to cylinder. Swelling results from the formation of vacuoles between the external membrane and the rest of the chloroplast (blebs), by increase in interlamellar spacing and by the formation of vacuoles between the lamellæ. The interlamellar vacuoles form by the lamellæ rounding up and coelescing to enclose the granular interlamellar material. Quantitative results for the volume : osmotic pressure relations, the volume : $p H$ relations, the surface charge, and the apparent free space for potassium chloride show that swelling is an osmotic process. The osmotic gradients arise from (a) a Donnan system associated with the interlamellar material, and (b) from diffusible solutes present in the interlamellar solution. The high values for the apparent free space and the volume: $p \mathrm{H}$ 